\title{
Maternal risk factors for neonatal jaundice: a hospital-based cross- sectional study in Tehran
}

\author{
Reza Tavakolizadeh (1), Anahita Izadi (2), Golnar Seirafi (3), Leila Khedmat (4), Sayed \\ Yousef Mojtahedi (5)
}

(1) Department of Pediatrics, Tehran University of Medical Sciences, Tehran, Iran; (2) Department of Pediatric Infection Disease, Tehran University of Medical Science, Tehran, Iran; (3) School of Medicine, Ziaeian Hospital, Tehran University of Medical Sciences, Tehran, Iran; (4) Department of Social Medicine, Tehran University of Medical Sciences, Tehran, Iran; (5) Department of Pediatrics, Ziaeian Hospital, Tehran University of Medical Sciences, Tehran, Iran

This article is distributed under the terms of the Creative Commons Attribution Noncommercial License (CC BY-NC 4.0) which permits any noncommercial use, distribution, and reproduction in any medium, provided the original author(s) and source are credited.

\begin{abstract}
Diagnosis and timely treatment of neonatal jaundice is critical to preventing its dangerous side effects. Knowing the predisposing factors of neonatal jaundice is still a serious debate, which can be effective in controlling jaundice and the primary problem. The aim of this study was to evaluate maternal risk factors that contribute to the Hyperbilirubinemia among newborns admitted to Imam Khomeini and Ziaeean hospitals during 2015. We collected random samplings for the current study. Medical records for all newborns with jaundice were examined for risk factors associated with Hyperbilirubinemia. All variables were analyzed by SPSS software, version 19. Chi-square test and T-test were applied to evaluate qualitative and quantitative data, respectively. Our findings revealed that maternal age, weight, BMI, WBC, $\mathrm{Hb}$, PLT, birth in the first pregnancy, numbers of pregnancies and prolonged delivery were significantly associated with bilirubin levels. Preventing the risk correlated with maternal factors or identifying neonates with these risk factors is important in effective management of infants. Therefore, the evaluation of neonatal jaundice in health care services should always be considered as a fundamental policy.
\end{abstract}

Key Words: Neonatal jaundice, bilirubin, pregnancy, risk factors, health care

Eur J Transl Myol 28 (3): 257-264, 2018

\begin{abstract}
Neonatal jaundice is a common condition that occurs during the transitional period after birth. ${ }^{1-3}$. This unpreventable condition occurrs in $60 \%$ of term and $80 \%$ of preterm neonates all over the word. Jaundice is one of the most common causes of neonatal readmission to hospital. ${ }^{1}$ It usually begins on the second day after birth and lasts two to three days to reach normal levels of bilirubin in most cases without treatments., ${ }^{4,5}$ On the other hand, neonate population may show severe jaundice, or even jaundice that develops into acute bilirubin encephalopathy or kernicterus. ${ }^{6,7}$ Hyperbilirubinemia is primarily important because there is a close relationship between the increase in unconjugated bilirubin levels and neurotoxic effects that can lead to long-term complications such as cerebral palsy, kernicterus and hearing impairment. ${ }^{8-10}$ Severe jaundice is a serious life-threatening problem, and several factors interfere with the development of severe
\end{abstract}

jaundice, which can be related to genetic and/or geographic variables. ${ }^{7}$ Early diagnosis of infants at high risk of severe hyperbilirubinemia plays an important role in facilitating the timely and appropriate prevention of disease within the first 14 days of birth. ${ }^{7,11}$ Clinical symptoms of hyperbilirubinemia are primarily seen in the head and face, and then affect the organs of the trunk and the limb due to increased serum levels of bilirubin. It is noteworthy that increasing hemoglobin release from breakdown of red cells due to high hemoglobin leads to jaundice at birth. ${ }^{12,13}$. This disease may also be due to decreased hepatic excretion of bilirubin. ${ }^{14,15}$ Since jaundice may have serious side effects on the health of infants, consideration should be given to its associated factors in newborns. Kernicterus is one of the most important diseases that complications of the disease are sometimes so dangerous. Considering the fact that jaundice is one of the common causes of 
Table1. Association of some maternal factors with the level of bilirubin

\begin{tabular}{|c|c|c|c|c|c|c|c|}
\hline \multicolumn{2}{|c|}{ Bilirubin } & \multirow{2}{*}{$\begin{array}{c}\text { Mother's age } \\
0.02\end{array}$} & \multirow{2}{*}{$\begin{array}{c}\begin{array}{c}\text { Mother's } \\
\text { breathing } \\
\text { number }\end{array} \\
0.44\end{array}$} & \multirow{2}{*}{$\begin{array}{c}\begin{array}{c}\text { Mother's } \\
\text { heart rate }\end{array} \\
0.85\end{array}$} & \multirow{2}{*}{$\begin{array}{c}\text { Weight } \\
0.001\end{array}$} & \multirow{2}{*}{$\begin{array}{c}\text { Height } \\
0.19\end{array}$} & \multirow{2}{*}{$\begin{array}{l}\text { BMI } \\
0.01\end{array}$} \\
\hline & p-value & & & & & & \\
\hline \multirow[t]{2}{*}{$10-14.9$} & Mean & 29.37 & 14.93 & 89.04 & 80.43 & 162.65 & 30.42 \\
\hline & SD & 6.21 & 2.91 & 6.04 & 7.42 & 4.09 & 2.94 \\
\hline \multirow[t]{2}{*}{$15-19.9$} & Mean & 25.94 & 14.48 & 88.42 & 75.03 & 161.45 & 28.78 \\
\hline & SD & 5.91 & 2.39 & 6.13 & 5.48 & 3.54 & 1.89 \\
\hline \multirow[t]{2}{*}{$20-24.9$} & Mean & 28.17 & 13.67 & 88.33 & 78.50 & 160.83 & 30.43 \\
\hline & SD & 5.71 & 2.73 & 1.63 & 7.18 & 3.06 & 3.55 \\
\hline \multirow[t]{2}{*}{ Total } & Mean & 28.81 & 14.82 & 88.92 & 79.54 & 162.41 & 30.17 \\
\hline & SD & 6.24 & 2.83 & 5.96 & 7.38 & 4.00 & 2.87 \\
\hline
\end{tabular}

SD, Standard Deviation

hospitalization of newborns, attention can be paid to timely diagnosis and prevention of it. On the other hand, the rapid treatment of jaundice or timely prevention will be cost-effective in annual costs due to reduced hospitalization of newborns. To the best of our knowledge, the evaluation of the causes and risk factors of neonatal jaundice in newborns has not been comprehensively performed in Iran, while we are confronted with the spread of the disease among the newborns. Therefore, it is advisable to have a systematic and effective program for evaluation of causes and risk factors of jaundice in newborns. Prevention of jaundice risks requirs extensive and accurate analyses that should be continuously and repeatedly peformed. The present study was set out to assess the effects of maternal factors on neonatal jaundice with the aim of determining modifiable risk factors to reduce occurrence and consequences of severe jaundice in newborns.

\section{Materials and Methods}

\section{Ethical considerations}

All ethical principles of the Helsinki II declaration were followed. Newborns' parents were informed and written consent forms were collected.

\section{Data Collection}

This cross-sectional study was performed on 2207 term newborns ( $<15$ days) with hyperbilirubinemia $(>15$ $\mathrm{mg} / \mathrm{dl})$, who admitted to the neonatal intensive unit of the Ziaeean and Imam Khomeini Hospitals, Tehran, Iran, from April 2010 to May 2016. The records of all infants in terms of the maternal risk factors for neonatal jaundice have been investigated. Neonates born with jaundice in the birth admission were selected based on the neonatal outcome indicator. Data were obtained from medical records and interview sessions with the mothers by study staff. A checklist consisting of maternal demographic data and other data was provided for collecting data. Maternal information

Maternal information, including maternal age during pregnancy (over 35 and under the age of 18), first pregnancy, number of pregnancy, inter-pregnancy intervals of 3 years, type of delivery, Oxytocin Induction of labor, premature rupture of membranes (PROM), prolonged labor, cesarean section, multiple birth in the current pregnancy, respiratory rate during pregnancy, number of heart beats during pregnancy, maternal weight during pregnancy, body mass index, losing weight during pregnancy, history of abortion, were obtained from all mothers.

Inclusion criteria: Getting jaundice.

Exclusion criteria: Exclusion criteria included incomplete medical records that were beyond the control of the researcher; however, the additional sample size was considered to be about $20 \%$.

Sample size calculation

\begin{tabular}{|c|c|c|c|c|}
\hline alfa $=$ & 0.05 & $Z_{1-a / 2=}$ & 1.961150776 & \\
\hline $\mathrm{d}=$ & 0.03 & & & $n=\frac{21-\frac{1}{2}}{2}$ \\
\hline $\mathrm{p}=$ & 0.96 & $\mathrm{n}=$ & 165 & \\
\hline
\end{tabular}

An additional 20 percent sample size was added to prevent loss and withdrawal. $\mathrm{p}=$ first pregnancy as previously described. ${ }^{24,25}$ The sample size was finally calculated as 200 . The data were subsequently collected and entered in the questionnaire, followed by statistical analysis based on SPSS software version 19. the obtained data was entered into cod sheet and master sheet. Qualitative variables were presented as frequency, while quantitative variables were calculated as mean, range, and standard deviation. Chi-square test was applied to examine qualitative data, while 
Maternal risk factors for neonatal jaundice

Eur J Transl Myol 28 (3): 257-264, 2018

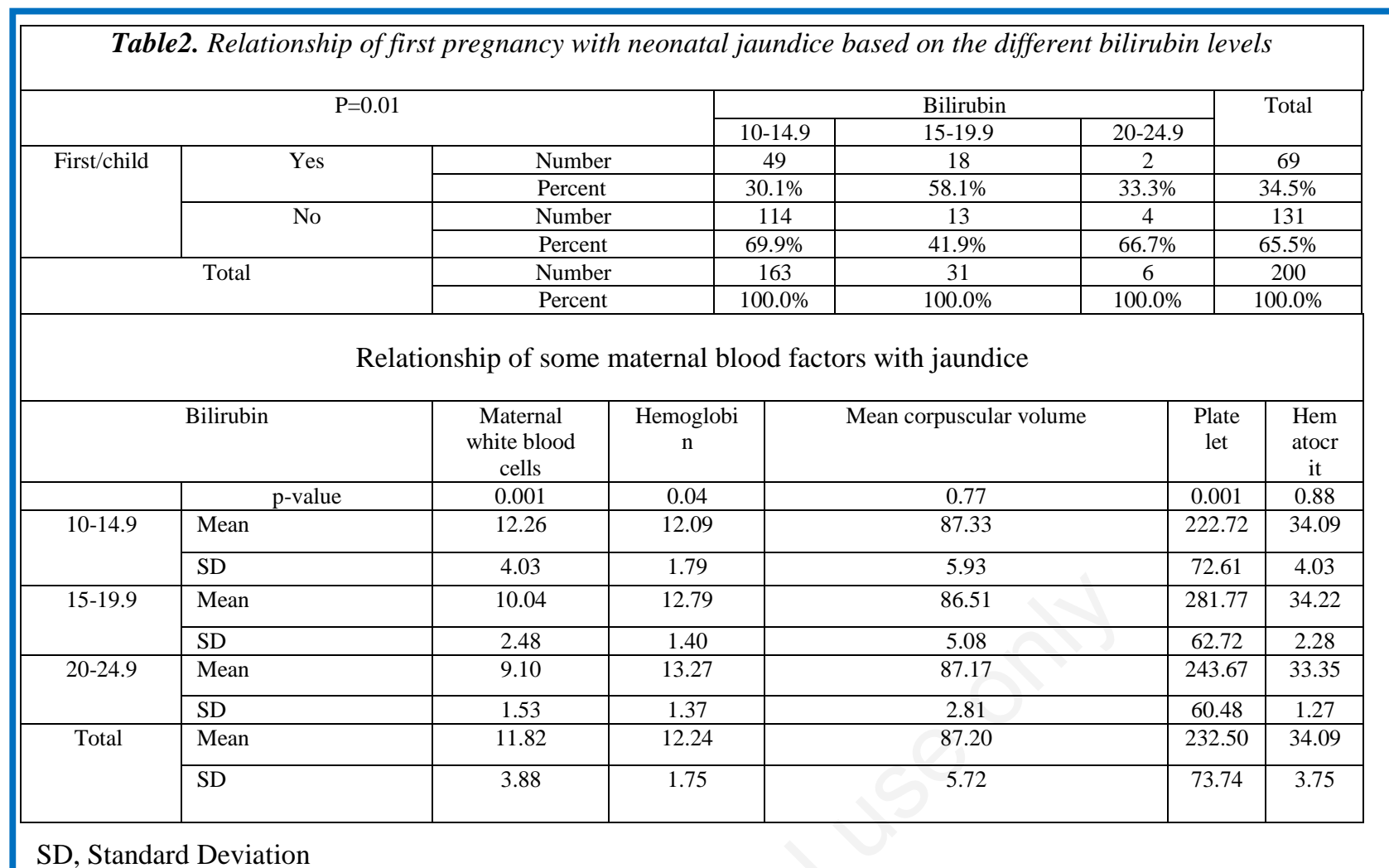

quantitative data were statically analyzed by T-test, $\mathrm{p}<$ 0.05 was considered statistically significant.

\section{Results and Discussion}

A list of maternal data is provided in Table 1. Regarding the mean age of the mother, the maternal age was significantly associated with different levels of bilirubin $(\mathrm{p}=0.02)$, indicating a significant correlation of maternal age with incidence of jaundice. Maternal weight, and BMI showed also significant differences among different levels of bilirubin $(\mathrm{p}=0.001 ; \mathrm{p}=0.01)$. As matter of fact, our findings suggest that the aforementioned variables were associated with neonatal jaundice. Respiratory rate at delivery, maternal heart rate and height had a significant difference at various levels of bilirubin, and were found to be linked to incidence of jaundice $\quad(\mathrm{p}=0.44 ; \mathrm{p}=0.85 \mathrm{p}=0.19)$. Table 2 shows the association of some maternal blood factors with jaundice. The statistical analysis revealed that maternal WBC, PLT and $\mathrm{Hb}$ had a significant relationship with jaundice $(\mathrm{p}=0.001 ; \mathrm{p}=0.001 ; \mathrm{p}=$ 0.04), but maternal $\mathrm{MCV}$, and HCT did not show significant correlation with bilirubin levels $(\mathrm{p}=0.77$; $\mathrm{P}$ $=0.88$ ). There is a significant difference in terms of birth in the first pregnancy among neonates with different levels of bilirubin ( $p=0.01$; Table 2). Our findings also indicate that the numbers of pregnancies were more likely to be referred for bilirubin levels $(p=0.00$; Table 3 ). In addition, interpregnancy interval of less than 3 years was not found to be linked to hyperbilirubinemia $(p=0.9$; Table 3$)$. Table 4 shows that $30.1 \%$ of infants in the first maternal delivery had a bilirubin level of 10 to 14.9 , followed by bilirubin levels of $15-19.9(58.1 \%)$ and bilirubin levels of 20- 24.9 $(33.3 \%)$. Table 4 demonstrates that $38.7 \%$ of natural childbirth (Vaginal delivery) was categorized to the bilirubin level, where ranged from 10-14.9; while the bilirubin level in the range of $15-19.9 \mathrm{mg} / \mathrm{dL}$ was attributed to a frequency of $54.8 \%$; Furthermore, bilirubin values ranged from $20-24.9 \mathrm{mg} / \mathrm{dL}$ in $33.3 \%$ of neonates. The delivery mode was not associated with the incidence of hyperbilirubinemia $(p=0.2$; Table 4). Regarding to oxytocin infusion, there was no significant difference between oxytocin infusion and disease incidence ( $p=0.5$; Table 4). According to the data of this study, there was a significant relationship between prolonged delivery and the incidence of neonatal jaundice $(p=0.03$, Table 4). Moreover, $46.6 \%$ of infants, who showed premature rupture of membranes (PROM), had a bilirubin level in the range of 10-14.9 $\mathrm{mg} / \mathrm{dL}$, followed by bilirubin levels in the range of 15 $19.9(61.3 \%)$ and $20-24.9 \mathrm{mg} / \mathrm{dL}$ (33.3\%). No association was found between PROM and different levels of bilirubin $(p=0.2$, Table 4$)$, Om the ther hand neonates with different levels of bilirubin had no significant difference in maternal cesarean section $(\mathrm{p}=$ 0.1 , Table 5). As shown in Table 5, 16\% of infants delivered by a multiple pregnancy showed a bilirubin level between $10-14 \mathrm{mg} / \mathrm{dL}$. 10-14.9; while the bilirubin level in the range of $15-19.9 \mathrm{mg} / \mathrm{dL}$ was attributed to a frequency of $6.5 \%$ and bilirubin values ranged from 20 $24.9 \mathrm{mg} / \mathrm{dL}$ in $0 \%$ of neonates. It is noteworthy that no 
Maternal risk factors for neonatal jaundice

Eur J Transl Myol 28 (3): 257-264, 2018

\begin{tabular}{|c|c|c|c|c|c|c|c|}
\hline \multicolumn{8}{|c|}{ Table 3. Correlation of numbers of pregnancies with neonatal jaundice based on the different bilirubin levels } \\
\hline \multirow{2}{*}{\multicolumn{4}{|c|}{$\mathrm{P}=0.001$}} & \multicolumn{3}{|c|}{ Bilirubin } & \multirow{3}{*}{\begin{tabular}{|c|} 
Total \\
69
\end{tabular}} \\
\hline & & & & \multirow{2}{*}{$\begin{array}{c}10-14.9 \\
49\end{array}$} & $15-19.9$ & \multirow{2}{*}{$\frac{20-24.9}{2}$} & \\
\hline \multirow[t]{14}{*}{ number/of/pregnancy } & \multirow[t]{2}{*}{1.00} & \multicolumn{2}{|c|}{ Number of (first pregnancy) } & & 18 & & \\
\hline & & \multicolumn{2}{|l|}{ Percent } & $30.1 \%$ & $58.1 \%$ & $33.3 \%$ & $34.5 \%$ \\
\hline & \multirow[t]{2}{*}{2.00} & \multicolumn{2}{|c|}{ Number of (second pregnancy) } & 57 & 5 & 1 & 63 \\
\hline & & \multicolumn{2}{|c|}{ Percent } & $35.0 \%$ & $16.1 \%$ & $16.7 \%$ & $31.5 \%$ \\
\hline & \multirow{2}{*}{3.00} & \multicolumn{2}{|c|}{ Number of (third pregnancy) } & 32 & 6 & 2 & 40 \\
\hline & & \multicolumn{2}{|c|}{ Percent } & $19.6 \%$ & $\frac{6}{19.4 \%}$ & $33.3 \%$ & $20.0 \%$ \\
\hline & \multirow[t]{2}{*}{4.00} & \multicolumn{2}{|c|}{ Number of (fourth pregnancy) } & 21 & 0 & 0 & 21 \\
\hline & & Percent & & $12.9 \%$ & $0 \%$ & $0 \%$ & $10.5 \%$ \\
\hline & 5.00 & Number of (fifth pr & gnancy) & 0 & 2 & 1 & 3 \\
\hline & & Percent & & $0 \%$ & $6.5 \%$ & $16.7 \%$ & $1.5 \%$ \\
\hline & 6.00 & Number of (sixth pr & gnancy) & 3 & 0 & 0 & 3 \\
\hline & & Percent & & $1.8 \%$ & $0 \%$ & $0 \%$ & $1.5 \%$ \\
\hline & 8.00 & Number of (seventh & regnancy) & 1 & 0 & 0 & 1 \\
\hline & & Percent & & $0.6 \%$ & $0 \%$ & $0 \%$ & $0.5 \%$ \\
\hline Total & & Number & & 163 & 31 & 6 & 200 \\
\hline & & Percent & & $100.0 \%$ & $100.0 \%$ & $100.0 \%$ & $\begin{array}{c}100.0 \\
\%\end{array}$ \\
\hline & Relati & $p$ between the number & f pregnanci & s and neonat & al jaundice & & \\
\hline & $\mathrm{P}=0.9$ & & & Bilirubin & & Total & \\
\hline & & & $10-14.9$ & $15-19.9$ & $20-24.9$ & & \\
\hline interpregnancy interval & No & Number & 106 & 20 & 4 & 130 & \\
\hline or less trlan 5 years & & Percent & $65.0 \%$ & $64.5 \%$ & $66.7 \%$ & $65.0 \%$ & \\
\hline & Yes & Number & 57 & 11 & 2 & 70 & \\
\hline & & Percent & $35.0 \%$ & $35.5 \%$ & $33.3 \%$ & $35.0 \%$ & \\
\hline Total & & Number & 163 & 31 & 6 & 200 & \\
\hline & & Percent & $100.0 \%$ & $100.0 \%$ & $100.0 \%$ & $100.0 \%$ & \\
\hline
\end{tabular}

significant difference was found between twins and disease incidence among neonates with different levels of bilirubin $(\mathrm{p}=0.2)$. The history of abortion did not show a significant relationship with the incidence of disease $(\mathrm{p}=0.2$; Table 5).

Jaundice is a complication that may lead to death in the first month of birth and infants who are still alive suffer from many disorders including mental retardation (Intellectual disability), mobility and balance disorders, seizures, hearing loss at high frequencies, and speech impairment. Protecting and promoting the health of infants as a vulnerable group in the health services has a special place. Therefore, evaluation of neonatal jaundice in health care services should always be considered as a fundamental policy. Nearby, early detection of its risk factors can be effective in preventing disease in highrisk mothers-infants. Our study showed that maternal age, weight, BMI, WBC, Hb, PLT, birth in the first pregnancy, numbers of pregnancies and prolonged delivery were significantly correlated with bilirubin levels. Maternal age was found to be statistically significant in statistical analysis. Srivastav et al., found higher serum bilirubin levels in neonates of younger mothers. ${ }^{16}$ A previous study has also suggested that maternal age $\geq 30$ years can be linked to increased risk for neonates. ${ }^{17}$ Another study by Özdek et al. demonstrated that mothers who have more weight than the advised amount may be at risk of neonatal jaundice. ${ }^{18}$ Conversely, many studies have reported that this variable was not correlated with hyperbilirubinemia. ${ }^{19,20}$ In the present study, the mean age of mothers in patients was determined as 28.8 years (Maximum: 43 years; Minimum: 17 years). Based on the findings, the mean age of mothers in newborns with moderate jaundice was lower than other forms of disease and the most cases of jaundice were observed in the first pregnancy $(34.5 \%$, 69 cases). In other studies, CBC level and its related parameters have not been studied in the mother. One of the strengths of this study is to examine the level of maternal blood parameters. It seems that the levels of WBC, Hb, and PLT have a significant correlation with the incidence of neonatal jaundice. However, it was found that that there was not an increasing risk for neonatal jaundice with maternal 


\begin{tabular}{|c|c|c|c|c|c|c|c|c|}
\hline \multicolumn{9}{|c|}{ Table 4. Relationship between delivery method and jaundice in different levels of bilirubin } \\
\hline \multicolumn{5}{|c|}{$\mathrm{P}=0.2$} & \multicolumn{3}{|c|}{ Bilirubin } & \multirow[t]{2}{*}{ Total } \\
\hline & & & & & $10-14.9$ & $15-19.9$ & $20-24.9$ & \\
\hline \multirow{4}{*}{\multicolumn{3}{|c|}{ Type of delivery }} & \multirow{2}{*}{$\begin{array}{l}\text { Normal vaginal } \\
\text { delivery (NVD) }\end{array}$} & Number & 63 & 17 & 2 & 82 \\
\hline & & & & Percent & $38.7 \%$ & $54.8 \%$ & $33.3 \%$ & $41.0 \%$ \\
\hline & & & \multirow{4}{*}{$\begin{array}{l}\text { Caesarean section } \\
\text { (CS) }\end{array}$} & Number & 100 & 14 & 4 & 118 \\
\hline & & & & Percent & $61.3 \%$ & $45.2 \%$ & $66.7 \%$ & $59.0 \%$ \\
\hline \multirow{2}{*}{\multicolumn{3}{|c|}{ Total }} & & Number & 163 & 31 & 6 & 200 \\
\hline & & & & Percent & $100.0 \%$ & $100.0 \%$ & $100.0 \%$ & $100.0 \%$ \\
\hline \multicolumn{9}{|c|}{ Relationship between oxytocin infusion and jaundice in different levels of bilirubin } \\
\hline \multirow{2}{*}{\multicolumn{4}{|c|}{$\mathrm{P}=0.5$}} & \multicolumn{3}{|c|}{ Bilirubin } & \multirow{2}{*}{\multicolumn{2}{|c|}{ Total }} \\
\hline & & & & $10-14.9$ & $15-19.9$ & $20-24.9$ & & \\
\hline \multirow{4}{*}{\multicolumn{2}{|c|}{ Oxytosin injection }} & Yes & Number & 147 & 26 & 5 & & 178 \\
\hline & & & Percent & $90.2 \%$ & $83.9 \%$ & $83.3 \%$ & & $89.0 \%$ \\
\hline & & No & Number & 16 & 5 & 1 & & 22 \\
\hline & & & Percent & $9.8 \%$ & $16.1 \%$ & $16.7 \%$ & & $11.0 \%$ \\
\hline \multirow{2}{*}{\multicolumn{3}{|c|}{ Total }} & Number & 163 & 31 & 6 & & 200 \\
\hline & & & Percent & $100.0 \%$ & $100.0 \%$ & $100.0 \%$ & & $100.0 \%$ \\
\hline & Associa & on betwee & rolonged delivery & cidence of $j$ & aundice in $\mathrm{d}$ & ifferent level & Is of bilit & \\
\hline \multirow{2}{*}{\multicolumn{4}{|c|}{$\mathrm{P}=0.03$}} & \multicolumn{3}{|c|}{ Bilirubin } & \multirow{2}{*}{\multicolumn{2}{|c|}{ Total }} \\
\hline & & & & $10-14.9$ & $15-19.9$ & $20-24.9$ & & \\
\hline \multirow{4}{*}{\multicolumn{2}{|c|}{ Prolonged }} & \multirow[t]{2}{*}{ Yes } & Number & 72 & 20 & 1 & & 93 \\
\hline & & & Percent & $44.2 \%$ & $64.5 \%$ & $16.7 \%$ & & $46.5 \%$ \\
\hline & & \multirow[t]{2}{*}{ No } & Number & 91 & 11 & 5 & & 107 \\
\hline & & & Percent & $55.8 \%$ & $35.5 \%$ & $83.3 \%$ & & $53.5 \%$ \\
\hline \multirow{2}{*}{\multicolumn{3}{|c|}{ Total }} & Number & 163 & 31 & 6 & & 200 \\
\hline & & & Percent & $100.0 \%$ & $100.0 \%$ & $100.0 \%$ & & $100.0 \%$ \\
\hline \multicolumn{9}{|c|}{ Association between PROM and neonatal jaundice in different levels of bilirubin } \\
\hline \multirow{2}{*}{\multicolumn{3}{|c|}{$\mathrm{P}=0.2$}} & & irubin & & \multirow{2}{*}{\multicolumn{3}{|c|}{ Total }} \\
\hline & & & $10-14.9$ & $15-19.9$ & $20-24.9$ & & & \\
\hline \multirow[t]{4}{*}{ PROM } & \multirow[t]{2}{*}{ Yes } & Number & 76 & 19 & 2 & & 97 & \\
\hline & & Percent & $46.6 \%$ & $61.3 \%$ & $33.3 \%$ & & 48.5 & \\
\hline & No & Number & 87 & 12 & 4 & & 103 & \\
\hline & & Percent & $53.4 \%$ & $38.7 \%$ & $66.7 \%$ & & 51.5 & \\
\hline & & Number & 163 & 31 & 6 & & 200 & \\
\hline & & Percent & $100.0 \%$ & $100.0 \%$ & $100.0 \%$ & & 100.0 & \\
\hline
\end{tabular}

MCV, and HCT. Nevertheless, conversely, a study indicated that maternal haemoglobin was not demonstrated to affect the bilirubin levels in physiological jaundice. ${ }^{19}$ Further studies are needed to clarify the role of blood factors mentioned in the current study. Our finding suggested that birth in the first pregnancy, numbers of pregnancies and prolonged labor could be important risk factors in current study population. In our study population, some factors such as delivery mods, twins, interpregnancy interval of less than 3 years were found to be associated with neonatal jaundice. In agreements with previous studies, there was no an increasing risk for neonatal jaundice with the delivery mode, where was not correlated with the incidence of hyperbilirubinemia.

It has been previously reported that mode of delivery could be liked to jaundice and its severity 19,20-24 Contrary, it has been previously revealed that naturally 
Maternal risk factors for neonatal jaundice

Eur J Transl Myol 28 (3): 257-264, 2018

Table 5. Association between neonatal hyperbilirubinemia and cesarean section

\begin{tabular}{|c|c|c|c|c|c|c|c|}
\hline \multicolumn{8}{|c|}{ Table 5. Association between neonatal hyperbilirubinemia and cesarean section } \\
\hline \multirow{2}{*}{\multicolumn{3}{|c|}{$\mathrm{P}=0.1$}} & \multicolumn{3}{|c|}{ Bilirubin } & \multirow{2}{*}{\multicolumn{2}{|c|}{ Total }} \\
\hline & & & $10-14.9$ & $15-19.9$ & $20-24.9$ & & \\
\hline \multirow{4}{*}{$\begin{array}{l}\text { History of cesarean } \\
\text { section (CS) }\end{array}$} & \multirow[t]{2}{*}{ Yes } & Number & 58 & 6 & 3 & \multicolumn{2}{|c|}{67} \\
\hline & & Percent & $35.6 \%$ & $19.4 \%$ & $50.0 \%$ & \multicolumn{2}{|c|}{$33.5 \%$} \\
\hline & \multirow[t]{2}{*}{ No } & Number & 105 & 25 & 3 & \multicolumn{2}{|c|}{133} \\
\hline & & Percent & $64.4 \%$ & $80.6 \%$ & $50.0 \%$ & \multicolumn{2}{|c|}{$66.5 \%$} \\
\hline \multirow{2}{*}{\multicolumn{2}{|c|}{ Total }} & Number & 163 & 31 & 6 & \multicolumn{2}{|c|}{200} \\
\hline & & Percent & $100.0 \%$ & $100.0 \%$ & $100.0 \%$ & \multirow{2}{*}{\multicolumn{2}{|c|}{$\frac{100.0 \%}{\text { pregnancy (twin) }}$}} \\
\hline \multicolumn{6}{|c|}{ Correlation between neonatal hyperbilirubinemia and multiple births in the current pregnancy (twin) } & & \\
\hline \multirow{2}{*}{\multicolumn{3}{|c|}{$\mathrm{P}=0.2$}} & \multicolumn{3}{|c|}{ Bilirubin } & \multirow{2}{*}{\multicolumn{2}{|c|}{ Total }} \\
\hline & & & $10-14.9$ & $15-19.9$ & $20-24.9$ & & \\
\hline \multirow{4}{*}{$\begin{array}{l}\text { Multiple birth } \\
\text { in the current } \\
\text { pregnancy } \\
\text { (twin) }\end{array}$} & \multirow[t]{2}{*}{ YES } & Number & 26 & 2 & 0 & \multicolumn{2}{|c|}{28} \\
\hline & & Percent & $16.0 \%$ & $6.5 \%$ & $0 \%$. & \multicolumn{2}{|c|}{$14.0 \%$} \\
\hline & \multirow[t]{2}{*}{ NO } & Number & 137 & 29 & 6 & \multicolumn{2}{|c|}{172} \\
\hline & & Percent & $84.0 \%$ & $93.5 \%$ & $100.0 \%$ & \multicolumn{2}{|c|}{$86.0 \%$} \\
\hline \multirow{2}{*}{\multicolumn{2}{|c|}{ Total }} & Number & 163 & 31 & 6 & \multicolumn{2}{|c|}{200} \\
\hline & & Percent & $100.0 \%$ & $100.0 \%$ & $100.0 \%$ & \multicolumn{2}{|c|}{$100.0 \%$} \\
\hline \multicolumn{8}{|c|}{ History of abortion and risk of hyperbilirubinemia } \\
\hline \multirow{2}{*}{\multicolumn{3}{|c|}{$\mathrm{P}=0.2$}} & \multicolumn{4}{|c|}{ Bilirubin } & \multirow[t]{2}{*}{ Total } \\
\hline & & & $10-14.9$ & & & $20-24.9$ & \\
\hline History of & Yes & Number & 81 & & & 4 & 96 \\
\hline abortion & & Percent & $49.7 \%$ & & & $66.7 \%$ & $48.0 \%$ \\
\hline & No & Number & 82 & - & & 2 & 104 \\
\hline & & Percent & $50.3 \%$ & 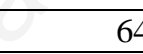 & & $33.3 \%$ & $52.0 \%$ \\
\hline Total & & Number & 163 & & & 6 & 200 \\
\hline & & Percent & $100.0 \%$ & & & $100.0 \%$ & $100.0 \%$ \\
\hline
\end{tabular}

delivered subjects are likely to be at higher risk for neonatal jaundice, when comparing with those born by cesarean section, indicating the importance of delivery mode as a risk factors for jaundice. ${ }^{25,26}$ The conflicting findings could be linked to types of variables, types of study, sample size and study condition, where can affect to data analysis. On the other hand, no significant difference was found between oxytocin infusion and disease incidence, while oxytocin is involved in bilirubin metabolism and has been described to be a risk factor for the development of neonatal jaundice, induction of labor with oxytocin may associated with hypoosmotic and lytic effects (increased red blood cell lysis), resulting in hyperbilirubinemia ${ }^{26-28}$. However, it is recommended that this factor be assessed with a higher sample size. Excessive application of oxytocin during labor and cesarean section have been defined as risk factors. ${ }^{25,26}$ In the present study, cesarean section was not found to be associated with hyperbilirubinemia. Hyperbilirubinemia might be exacerbated by cesarean section, in comparison to natural births ${ }^{11}$. On the other hand, mode of delivery has been not found to be significantly associated with incidence of hyperbilirubinemia. ${ }^{29}$ As mentioned in results, prolonged labor remained obviously linked to neonatal jaundice in our study population. In consist with the current study, Scrafford, et al, reported a significant association of prolonged labor with jaundice, possibly the clinical relationship between longer labor and cephalohematoma may play a role in this event. ${ }^{10,30}$ Furthermore, no significant association was found between PROM and neonatal jaundice, however PROM has been described to affect some of the parameters involved in the health of fetuses and infants, such as neonatal jaundice, platelet parameters and erythrocyte parameters ${ }^{31}$, Further evaluation are required to clarify the role some of mentioned variable that were not showed correlation with neonatal jaundice. Twins was not important risk factors in the current study, several reported risk factors were not found in the current study to be correlated with jaundice in neonates such as twins 32-35. As matter of fact twins was found to be correlated with hyperbilirubinemia in some investigations, but we did not find such association in our studies. In consist with our study, Scrafford et al. did not demonstrate correlation between twins and hyperbilirubinemia. ${ }^{10}$ The number of multiple births was very low in the current study $(\mathrm{N}=28)$, whereas caution should be observed in its interpretation; thereby, may reduce the statistical power for determining the statistically strong association 
between twins and jaundice in newborns. ${ }^{10}$ Preventing the risk correlated with maternal factors or identifying neonates with these risk factors is firstly important in effective management of infants, which can be taken into account by improving maternal and public health education. ${ }^{10,36,37}$.

The findings of this study indicated that there is a need for more epidemiological studies on characteristics of infants, and identifying the risk factors for hyperbilirubinemia. The history of abortion stillbirth or abortion did not show a significant relationship with the incidence of disease. History of stillbirth or abortion has been previously reported to be associated risk factor for neonatal hyperbilirubinemia, ${ }^{38,39}$ which are in agreement with our study. Further assessment of community-based detection of abortion history should be investigated in neonates. In future studies, the variables should be further evaluated in higher sample size. Finally, in order to promote health of infants, evaluation of neonatal jaundice should always be considered at all levels of health services.

\section{List of acronyms}

BMI - Body mass index

CS - Cesarean section

HB - Haemoglobin,

HCT - Hematocrit

MCV - Mean corpuscular volume

NVD - Normal vaginal delivery

PLT - Platelets

PROM - Premature rupture of membranes

WBC - White blood cells

$\mathrm{SD}$ - Standard deviation

\section{Author's contributions}

Each author contributed in equal part to the manuscript.

\section{Acknowledgments}

Funding: None.

\section{Conflict of Interest}

The authors declare no conflicts of interests.

\section{Ethical Publication Statement}

We confirm that we have read the Journal's position on issues involved in ethical publication and affirm that this report is consistent with those guidelines.

\section{Corresponding Author}

Sayed Yousef Mojtahedi, Department of Pediatrics, Ziyaeian Hospital, Abuzar Street, Qazvin Street, Tehran, PO: 1366736511, Tehran, Iran. Phone: +98 9121417467. E-mail: drmojtahed@yahoo.com

\section{E-mail of co-authors}

Reza Tavakolizadeh: rezatavakolizadeh@yahoo.com Anahita Izadi:dr.anahita.izadi@gmail.com Golnar Seirafi: g.seirafi@yahoo.com Leila Khedmat: l-khedmat@alumnus.tums.ac.ir

\section{References}

1. Jardine LA, Woodgate P. Neonatal jaundice. Am Fam Physician 2012;85:824-5.

2. Paul IM, Lehman EB, Hollenbeak CS, Maisels MJ. Preventable newborn readmissions since passage of the Newborns' and Mothers' Health Protection Act Pediatrics 2006;118:2349-358.

3. Hall RT, Simon S, Smith MT. Readmission of breastfed infants in the first 2 weeks of life. J Perinatol 2000;20:432-37.

4. Stoll BJ, Kliegman RM. Jaundice and hyperbilirubinemiain the newborn, Nelson textbook of pediatrics. 18th ed. Saunders, Philadelphia, 2007, pp. 592.

5. Fanaroff AA, Martin RJ. Neonatal-Perinatal medicine, diseases of the fetus and infant. 7 th ed. Mosby: Saunders; 2006;7:694.

6. Hameed NN, Na' Ma AM, Vilms R, Bhutani VK. Severe neonatal hyperbilirubinemia and adverse short-term consequences in Baghdad, Iraq. Neonatology 2011;100:57-63.

7. Greco C, Arnolda G, Boo NY, Iskander IF, Okolo AA, Rohsiswatmo R, et al. Neonatal Jaundice in Low- and Middle-Income Countries: Lessons and Future Directions from the 2015 Don Ostrow Trieste Yellow Retreat. Neonatology 2016;110:172-80.

8. Watchko JF. Identification of neonates at risk for hazardous hyperbilirubinemia: emerging clinical insights. Pediatr Clin North Am 2009;56:671-87.

9. Watchko JF. Kernicterus and the molecular mechanisms of bilirubin-induced CNS injury in newborns. Neuromolecular Med 2006;8:513-29.

10. Scrafford CG, Mullany LC, Katz J. Incidence and Risk Factors for Neonatal Jaundice among Newborns in Southern Nepal. Tropical medicine \& International Health?: TM \& IH 2013;18:1317-28.

11. National Institute for Health and Clinical Excellence. Neonatal jaundice. (Clinical guideline 98.) Available: www.nice.org.uk/CG98.2010.

12. Geiger AM, Petitti DB, Yao JF. Rehospitalisation for neonatal jaundice: risk factors and outcomes. Paediatr Perinat Epidemiol 2001;15:352-58.

13. Maisels MJ, Kring E. Length of stay, jaundice, and hospital readmission. Pediatrics 1998;101:995-8.

14. Dixon KT.Geiger AM, Petitti DB, Yao JFNewborn jaundice and kernicterus. Greater awareness and action needed. Adv Nurse Pract 2004;12:43-6.

15. Izsak J. Length of stay, jaundice, and hospital readmission. Pediatrics 1999;103:699-700. 


\section{Maternal risk factors for neonatal jaundice}

Eur J Transl Myol 28 (3): 257-264, 2018

16. Srivastav N, Pande US, Malik GK, et al. A study of serum bilirubin in neonates in relation to the maternal age. Indian J Med Sci 1999;53:158-61.

17. Norman $\mathrm{M}$, Åberg $\mathrm{K}$, Holmsten $\mathrm{K}$, et al. Predicting Nonhemolytic Neonatal Hyperbilirubinemia. Pediatrics 2015;136:1087-94.

18. Özdek S, Kul M, BarAkcan A, et al. The effect of the pre-pregnancy weight of the mother and the gestational weight gain on the bilirubin level of term newborn. J Matern Fetal Neonatal Med 2016;29:2434-7.

19. Agarwal V, Singh V, Goel SP, Gupta B. Maternal and neonatal factors affecting physiological jaundice in western U.P. Indian J Physiol Pharmacol 2007;51:203-6.

20. Linn S, Stephen C, Richard R, et al. Epidemiology of Neonatal bilirubinemia. Paediatrics 1985;75:770-72.

21. Sivasuriya M, Tan KL, Salmon YM. Neonatal serum bilirubin levels in spontaneous and induced labor. Br J Obstet Gynaecol 1978;85:619-23.

22. Esmailepour-Zanjani S, Safavi M, Jalali S, Abyane EE. Incidence and associated factoes of neonatal hyperbilirubinemia at Hedayat hospital. J Shahid Beheshti Sch Nurs Midwifery 2007;17:19-25.

23. Agarwal V, Singh V, Goel SP, Gupta B. Maternal and neonatal factors affecting physiological jaundice in western U.P. Ind J Physiol Pharmacol 2007;51:203-6.

24. Boskabadi H, Navaei M. Relationship between delivery type and jaundice severity among newborns referred to Ghaem Hospital within a 6year period in Mashhad. Iran J Obstet Gynecol Infertil 2011;14:15-21. Risk of hyperbilirubinemia in breast-fed infants. J Pediatr 2011;159:561-5.

25. Garosi E, Mohammadi F, Ranjkesh F. The relationship between neonatal jaundice and maternal and neonatal factors. Iranian J Neonatol 2016;7:37-40.

26. Hannam S, McDonnell M, Rennie JM. Investigation of prolonged neonatal jaundice. Acta Paediatr 2000;89:694-7.

27. Zarrinkoub F, Beigi A. Epidemiology of hyperbilirubinemia in the first 24 hours after birth. Tehran Univ Med J 2007;65:54-9.

28. Boskabadi H, Navaei M. Relationship between delivery type and jaundice severity among newborns referred to Ghaem Hospital within a 6- year period in Mashhad. Iran J Obstet Gynecol Infertil 2011;14:15-21.

29. American Academy of Pediatrics Subcommittee on Hyperbilirubinemia. Management of hyperbilirubinemia in the newborn infant 35 or more weeks of gestation. Pediatrics 2004;114:297316.

30. Liu J, Feng ZC, Wu J. The incidence rate of premature rupture of membranes and its influence on fetal-neonatal health: a report from mainland China. J Trop Pediatr 2010;56:36-42.

31. Olusanya BO, Akande AA, Emokpae A, Olowe SA. Infants with severe neonatal jaundice in Lagos, Nigeria: incidence, correlates and hearing screening outcomes. Trop Med Int Health 2009;14:301-10.

32. AAP Subcommittee on Neonatal Hyperbilirubinemia, Neonatal jaundice and kernicterus. Pediatrics 2001;108:763-5.

33. Bracci R, Buonocore G, Garosi G, et al. Epidemiologic study of neonatal jaundice. A survey of contributing factors. Acta Paediatr Scand Suppl 1989;360:87-92.

34. Huang A, Tai BC, Wong LY, et al. Differential risk for early breastfeeding jaundice in a multiethnic Asian cohort. Ann Acad Med Singapore 2009;38:217-24.

35. Moise KJ Jr. Management of rhesus alloimmunization in pregnancy. Obstet Gynecol 2002;100:600-11.

36. Bhutani VK, Zipursky A, Blencowe $\mathrm{H}$, et al. Neonatal hyperbilirubinemia and Rhesus disease of the newborn: incidence and impairment estimates for 2010 at regional and global levels. Pediatr Res 2013:74:86-100.

37. Jalali SZ, Saeidinia A, Poorabbas SM. Predictive factors of hyperbilirubinemia in newborns at University hospital in northern Iran. Indian $\mathbf{J}$ Experim Bio 2013;55:756-60.

38. Scrafford CG, Mullany LC, Katz J,et al.Incidence of and risk factors for neonatal jaundice among newborns in southern Nepal.Trop Med Int Health 2013;18:1317-28.

Submission: June 12, 2018

Revision received: June 29, 2018

Acceptance: June 30, 2018 